\title{
A Rotor Lamination Design for Surface Permanent Magnet Retention at High Speeds
}

\author{
Michael W. Degner, Richard Van Maaren, Member, IEEE, Azza Fahim, Donald W. Novotny, Fellow, IEEE, \\ Robert D. Lorenz, Senior Member, IEEE, and Charles D. Syverson
}

\begin{abstract}
A major problem in the design and manufacturing of surface mounted permanent magnet machines is reliably holding the permanent magnets in place at high speeds. This paper evaluates a unique rotor lamination design for a high pole number, permanent magnet alternator. This buried magnet design, which is capable of reliably holding the permanent magnets in place at high speeds, offers both easier and cheaper assembly when compared with the methods currently used in surface mounted permanent magnet machines. Finite element analysis is used to compare the buried magnet design with equivalent surface mounted designs and shows that the performance of the alternator is not significantly affected by the iron over the magnets. Experimental results from a prototype alternator further corroborate the FEA and show that the design is capable of operating at high speeds with no other means of magnet retention. In addition, an improvement in the buried magnet design which can reduce the lamination complexity is suggested and examined.
\end{abstract}

\section{INTRODUCTION}

$\mathbf{T}$ HE advent of high-energy product, rare-earth permanent magnet materials has brought about a resurgence in the use of permanent magnets to provide the field excitation for electric machines. The rare-earth permanent magnet materials allow machines of very high efficiency and energy densities to be built. The use of permanent magnets to provide the field excitation in an ac generator reduces the size and complexity of the generator. The slip rings and field excitation no longer have to be provided, and the high energy density of the permanent magnets allows the size and weight of the alternator to be reduced. One of the most important issues in the design and manufacturing of any permanent magnet machine is the method used to hold the magnets in place and to prevent them from flying off during operation due to centrifugal forces. Gluing or banding the magnets in place increases the cost and complexity of the manufacturing process, whereas, burying the magnets increases the magnet leakage flux and the complexity of the magnetic design and model.

A high pole number is desirable when a permanent magnet generator is used to source a dc bus through a diode bridge

Paper IPCSD 95-65, approved by the Electric Machines Committee of the IEEE Industry Applications Society for presentation at the 1994 IEEE Industry Applications Society Annual Meeting, Denver, CO, October 2-7. This work was supported by the Kohler Company, Kohler, WI, and the Wisconsin Electric Machine and Power Electronic Consortium (WEMPEC). Manuscript released for publication September 15, 1995

M. W. Degner, A. Fahim; D. W. Novotny, and R. D. Lorenz are with the University of Wisconsin-Madison, Madison, WI 53706 USA.

R. Van Maaren is with the Kohler Co, Kohler, WI 53044 USA

C. D. Syverson is with Syverson Consulting, North Mankato, MN 56001 USA

Publisher Item Identifier S 0093-9994(96)01578-2. rectifier. The high pole number increases the frequency of the generator output, thereby, reducing the demands on the dc bus capacitor to reduce the voltage ripple. If the alternator is being used to source a power converter it is not required to operate at constant speed, and in fact, its speed may vary significantly as long as it always meets the minimum voltage requirement for the dc bus. A high pole number necessitates an increase in the machine diameter to allow room for reasonably sized permanent magnets. A larger diameter increases the inertia of the alternator, but this increase in inertia is not a disadvantage if the increased inertia can be used as an energy storage element allowing the alternator to supply larger surge loads while still providing the minimum voltage requirements of the dc bus.

\section{Buried Magnet Design}

Typically a high pole number alternator has the permanent magnets mounted at the rotor surface with some sort of gluing or banding, using materials such as fiberglass, kevlar, or inconel, to hold the permanent magnets in place [2], [3]. Another possibility related to banding that has recently been suggested [4], [5] is the use of a solid "can" made of either magnetic or nonmagnetic material to surround the surface mounted magnets and hold them in place. A magnetic "can" of course increases the potential for leakage flux and core losses due to its high permeability and low resistance, but it is cheaper and mechanically stronger than many of the nonmagnetic options. To prevent the magnets from becoming loose at high speed the "can" or banding have to be pre-loaded when put in place. The pre-loading can be achieved by the use of thermal expansion and cooling in the case of a "can," or the stretching of the banding as it is applied over the permanent magnets.

An alternative to surface mounting or the use of a "can" to hold the magnets in place is to integrate the "can" into the rotor structure by burying the magnets below the surface. The combination of a high pole number and buried permanent magnets produces a rotor configuration where the permanent magnets are just below the rotor surface, but are securely held in place. Burying the permanent magnets allows for flat magnets to be used in place of the more expensive arced magnets required when banding or a "can" is used. In addition, the high pole number causes the chord length of the buried permanent magnets to be almost equal to the equivalent arc length of a surface mounted magnet, giving the buried magnet design many of the same properties of a surface mounted design. 


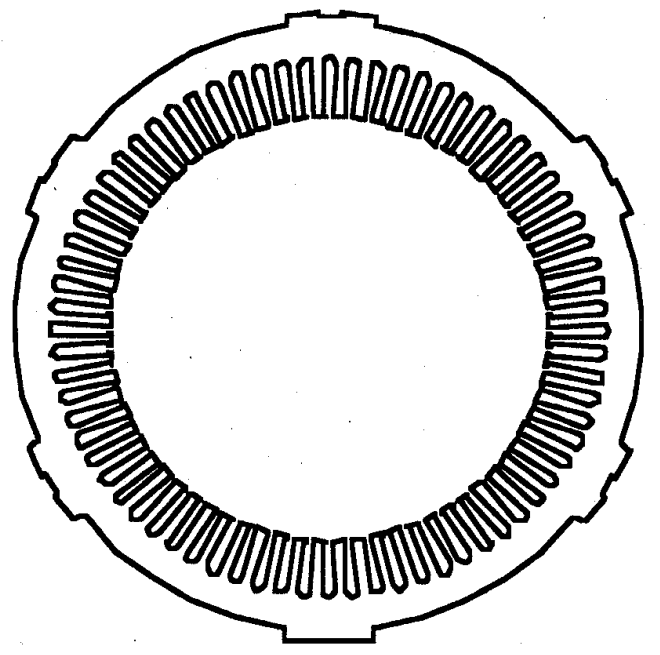

Fig. 1. Stator lamination.

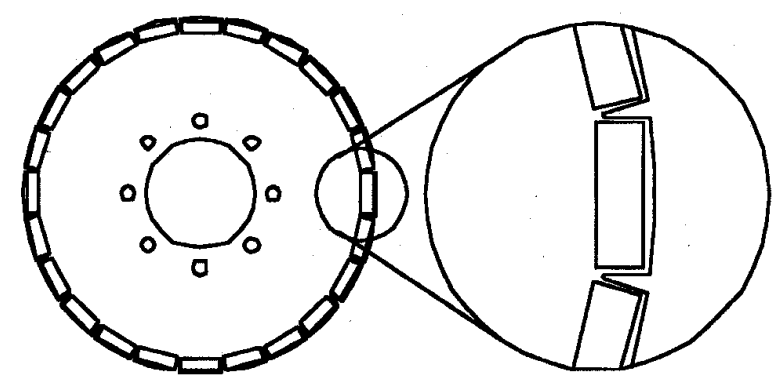

Fig. 2. Rotor lamination and close-up of magnet retaining caps.

Figs. 1 and 2 show a lamination design for a buried magnet alternator [reference removed] of the type described above. ${ }^{1}$ The stator lamination is similar to those used in induction or wound field synchronous machines. The rotor lamination on the other hand is unique from other buried magnet designs due to the high pole number. The high pole number allows the bridge over the top of the magnets to be very small and therefore very susceptible to the effects of saturation.

The benefits of this type of magnet retention include

- Magnets are securely held in place. The calculation of the required bridge structure to hold the magnets in place is straightforward.

- Easier assembly. The reluctance force produced by burying the magnets aids in assembly by pulling the magnets into place. In addition fewer steps are required since no additional means of securing the magnets in place is required.

- Lower magnet and assembly cost. Flat magnets can be used and fewer manufacturing steps reduces the overall cost of the design compared with other surface mounted magnet designs.

- Shorter effective air gap. The magnetic bridge used to hold the magnets in place effectively shortens the air

\footnotetext{
${ }^{1}$ The original lamination design was produced by C. Syverson as a consultant to the Kohler Company.
}

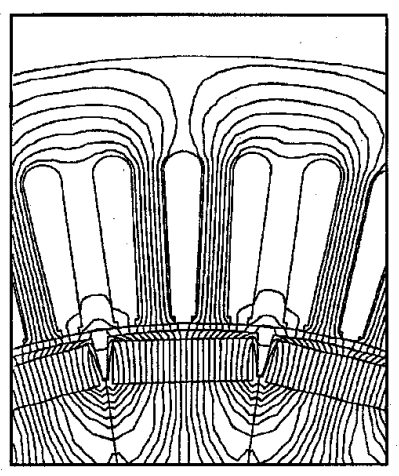

(a)

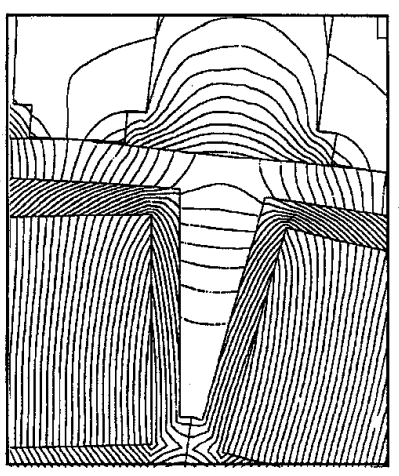

(b)
Fig. 3. Finite element analysis results showing open circuit magnetic vector potential. (a) View of one magnet bridge. (b) Close-up of bridge corners.

gap seen by the permanent magnets when compared with other flat, surface mounted magnet designs.

The disadvantages of this design include

- Increased rotor complexity and cost. If laminations are used for the rotor structure the die design is made more complex to allow for punching of magnet holes without bending the laminations.

- Increased leakage flux. The magnetic bridge holding the magnets in place provides an excellent leakage flux path.

Based on the design discussed above, an $8 \mathrm{kw}$ alternator was designed and built with 24 poles, a rotor diameter of 7.25 inches, and a stack length of 1.4 inches. The permanent magnets were Neodymium-Iron-Boron permanent magnets with an energy product of 37 MGOe. Using this alternator both finite element analysis and experimental measurements were used to assess the performance and characteristics of the buried magnet design.

\section{FINITE ELEMENT ANALYSIS}

The performance of the machine was examined using finite element methods to evaluate the magnetic leakage associated with the magnet retaining structure. Fig. 3 is a typical no load result, showing that the influence of the magnetic bridge is twofold:

1) It effectively shortens the air gap seen by the magnets and moves the magnet operating point closer to $\mathrm{B}_{r}$.

2) It increases the magnet leakage flux.

It is interesting to note from Fig. 3 that the portion of the magnetic bridge which saturates most heavily is not along the sides of the permanent magnets but along the surface of the permanent magnets near the bridge corner. This is shown very clearly in Fig. 4 which shows the calculated flux density vectors in the corner of the magnetic bridge.

For different rotor positions, relative to the stator, this portion of the magnetic bridge was always seen to be the most heavily saturated. This saturation in the bridge corner was caused not only by the leakage flux going down the sides of the permanent magnet through the magnetic bridge, but also by flux crossing the air gap to the stator, which may or may not be useful depending on rotor position. Since both 


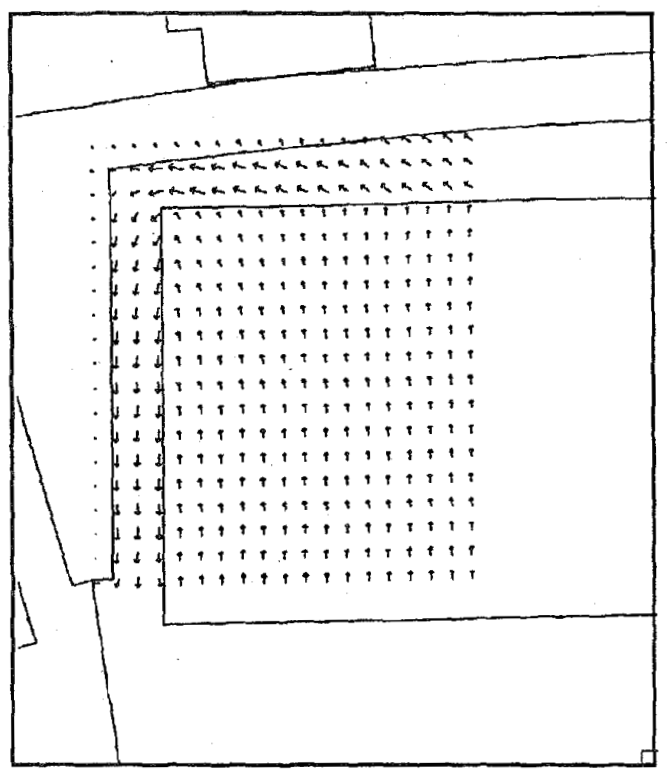

Fig. 4. Finite element analysis results showing open circuit flux density in magnetic bridge.

of these flux components go through the bridge corner their combined effect is to heavily saturate the bridge along the surface of the permanent magnet instead of along the side and thereby, effectively limiting the magnitude of this combined leakage and air gap flux. The fact that the top of the magnetic bridge saturates most heavily, instead of the sides, means that the dimension of the sides of the magnetic bridge is not as important as the dimension of the top of the magnetic bridge in limiting the amount of leakage flux. Saturation of the top corner of the magnetic bridge, therefore, effectively limits the amount of leakage flux produced by the bridge. The location of the heaviest saturation in the magnetic bridge suggests a very interesting way to improve the rotor design which will be discussed later.

To determine whether the use of the magnetic bridge structure to hold the permanent magnets in place causes a serious decline in the utilization of the permanent magnet material, a finite element analysis comparing an equivalent flat permanent magnet surface mounted design with the buried magnet design was performed. The results of this analysis were somewhat surprising. Although the magnetic bridge structure caused an increase in the leakage flux produced by the permanent magnets, the shortening of the air gap seen by the permanent magnets by the magnetic bridge resulted in almost exactly the same useful flux being produced by both the surface mounted and buried magnet designs. Obviously somewhat different results would be expected with an arced permanent magnet surface mounted design, but this would be offset somewhat by the longer airgap required for the nonmagnetic retention system used in an arced magnet design.

As seen from the stator, the magnetic bridge over the permanent magnets provides a path for the flux produced by the stator windings and, therefore, increases the $q$-axis inductance when compared with an equivalent surface mounted

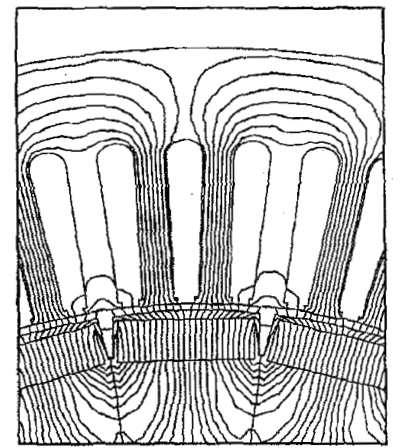

(a)

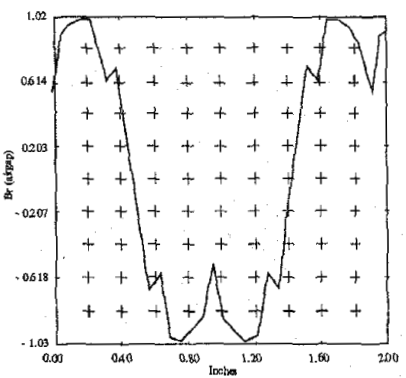

(b)
Fig. 5. Finite element analysis of machine under no load. (a) Magnetic vector potential. (b) Air gap flux density.

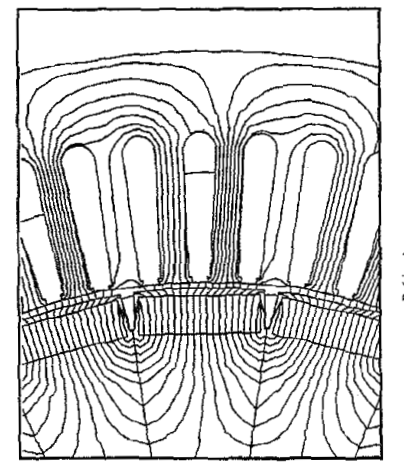

(a)

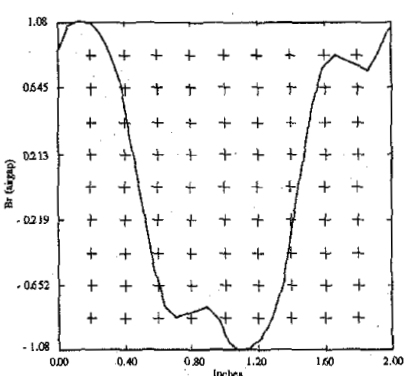

(b)
Fig. 6. Finite element analysis of machine under rated load. (a) Magnetic vector potential. (b) Air gap flux density.

design. On the other hand, the small dimensions of the magnet retaining cap causes it to be easily saturated, especially since the permanent magnets are already producing a significant amount of flux which must travel through the cap to the stator. Figs. 5 and 6 show the magnetic vector potential and air gap flux density finite element solution for the machine under no load and rated load, respectively.

The small dimensions of the magnetic bridge, and the ease with which it saturates, means that the inductance of the stator windings will vary significantly from no load to full load. This variation is insignificant, however, when compared with load impedance seen by the alternator which dominates the machine reactance for all but nearly short circuit conditions. In fact, the saturated value for the machine reactance can be used for all loading conditions with reasonable results, since the load impedance is so dominant at light loading.

\section{EXPERIMENTAL RESULTS}

A prototype machine using the laminations illustrated in Figs. 1 and 2 was constructed and tested both under ac and dc (rectifier) loading. Fig. 7 shows the measured external characteristic along with a predicted characteristic based on FEA results and conventional design calculations [1]. A significant portion of the error between the measured and calculated data 


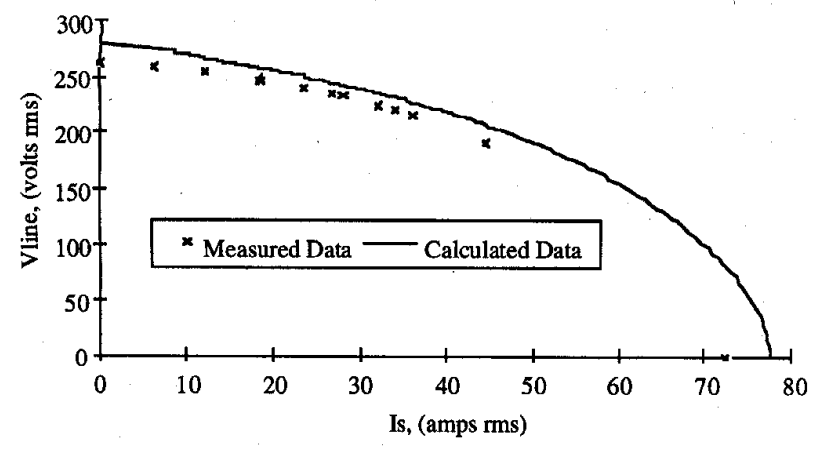

Fig. 7. Measured and predicted external voltage characteristic at $3600 \mathrm{r} / \mathrm{min}$ for a resistive load.

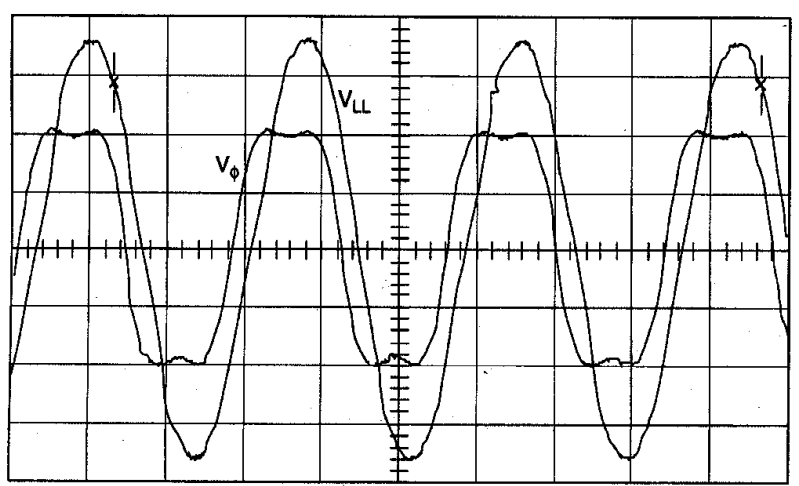

Fig. 8. Measured open circuit voltage waveforms at $1800 \mathrm{r} / \mathrm{min}(0.5 \mathrm{~ms}$ per div, $100 \mathrm{~V}$ per div).

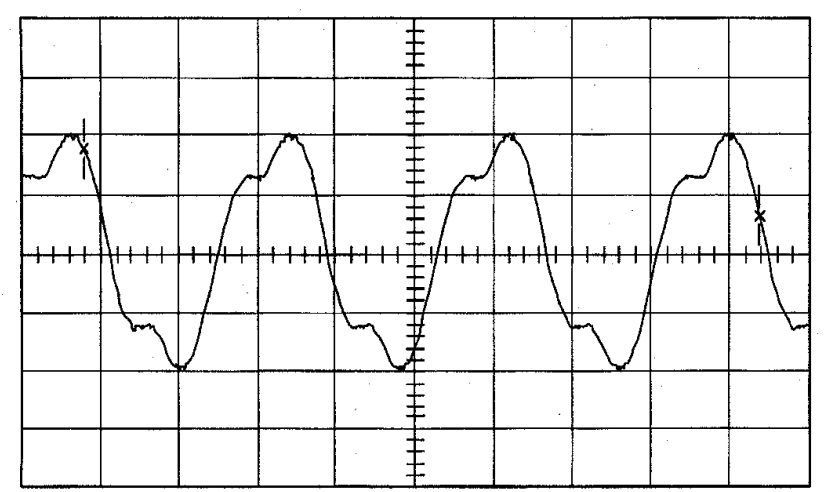

Fig. 9. Measured phase voltage waveform at $1800 \mathrm{r} / \mathrm{min}$ and rated load (resistive) $(0.5 \mathrm{~ms}$ per div, $100 \mathrm{~V}$ per div).

in Fig. 7 is caused by the error in the calculated open circuit voltage.

Figs. 8 and 9 show the prototype alternator's measured open circuit and rated load (resistive) voltage waveforms, respectively. Comparing the phase voltage waveforms with the FEA air gap flux densities shown in Figs. 5 and 6 shows excellent qualitative agreement.

\section{IMPROVEMENTS IN THE DESIGN}

The fact that the top of the magnet retaining bridge and not the side of the magnet retaining bridge was the element that limited the amount of leakage flux suggested a possible

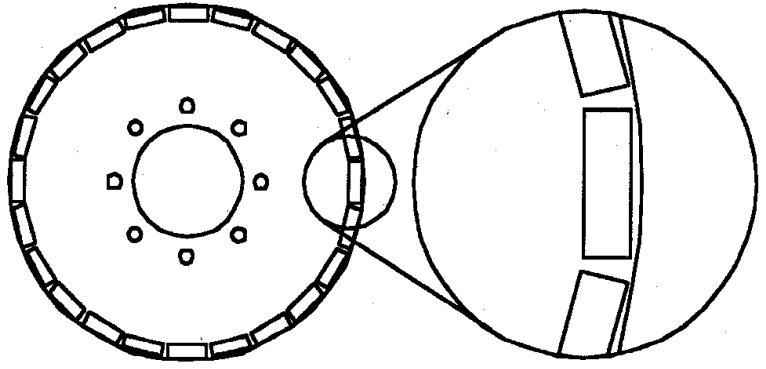

Fig. 10. Notchless rotor lamination deșign.

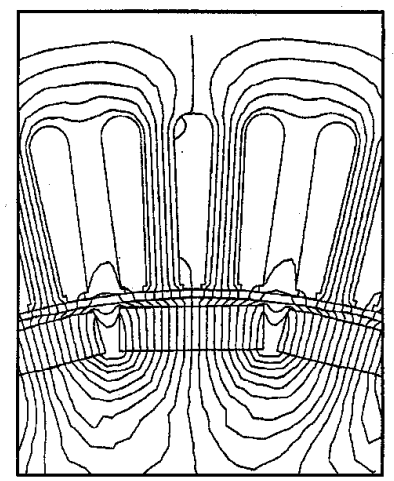

(a)

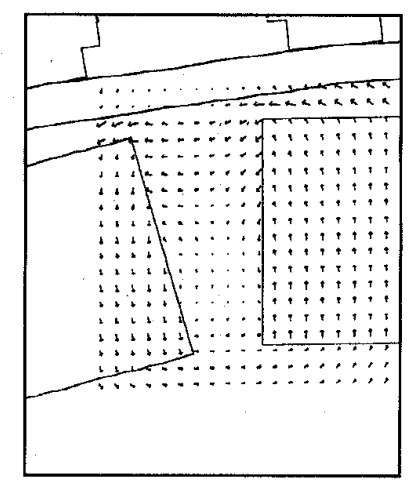

(b)
Fig. 11. Finite element analysis results showing open circuit condition for notchless rotor in $q$-axis position relative to stator slots. (a) Magnetic vector potential. (b) Close-up of flux density.

way to improve the alternator design by removing the notch in the rotor laminations between the permanent magnets. Fig. 10 shows the rotor lamination with the notch removed.

The potential benefits of removing the notch include

- increased rotor lamination stiffness;

- simplified lamination die with longer die life;

- decreased saliency. Removal of the notch decreases the saliency of the machine, also reducing the cogging torque;

- lower losses and acoustical noise. Removal of the notch smoothes out the air gap flux density reducing the losses and noise in both the rotor and stator laminations.

Figs. 11 and 12 show the FEA results for a notchless rotor at no load. In Fig. 11, which shows the rotor in the $q$-axis position relative to the stator slots, the total useful (mutual) flux was found to be the same as for the notched rotor. For the $d$-axis rotor position shown in Fig. 12, the useful flux was between $5-10 \%$ less than for the notched rotor case. This small reduction in flux can be readily compensated for by adjusting the turns and the advantages of a notchless design appear to outweigh the small loss of useful flux.

Based upon this analysis a rotor lamination without notches, but otherwise identical to the original in Fig. 2, was fabricated and used to construct a second machine. Tests were then run in succession on the two machines using the same test equipment and personnel. The results are presented in Table I.

As can be seen from Table $I$, the notchless machine produces slightly lower output voltage for all load conditions averaging about $2.7 \%$ less voltage over the five test points in the table. 


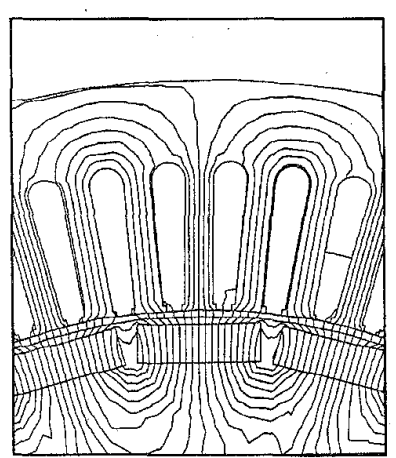

(a)

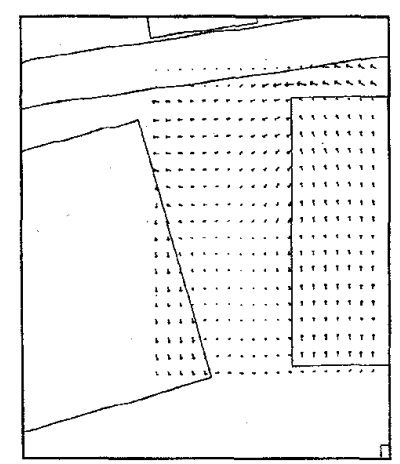

(b)
Fig. 12. Finite element analysis results showing open circuit condition for notchless rotor in $d$-axis position relative to stator slots. (a) Magnetic vector potential. (b) Close-up of flux density.

TABLE I

COMPARISON OF NOTCHED AND NOTCHLESS ROTORS 3600 RPM-FULL WAVE RECTIFIED OUTPUT

\begin{tabular}{|c|l|l|}
\hline \multicolumn{3}{|c|}{ Notchless } \\
\hline Vdc (V) & Idc (A) & Eff(\%) \\
\hline 331 & 4.0 & 60.9 \\
\hline 319 & 8.0 & 73.9 \\
\hline 303 & 14.5 & 82.5 \\
\hline 291 & 23.8 & 86.2 \\
\hline 276 & 33.3 & 86.9 \\
\hline
\end{tabular}

\begin{tabular}{|c|l|l|}
\hline \multicolumn{3}{|c|}{ Notched } \\
\hline$V_{d c}(\mathrm{~V})$ & Idc $(\mathrm{A})$ & Eff(\%) \\
\hline 341 & 4.1 & 59.8 \\
\hline 329 & 8.4 & 73.8 \\
\hline 312 & 14.8 & 80.1 \\
\hline 297 & 24.3 & 84.6 \\
\hline 283 & 33.3 & 86.6 \\
\hline
\end{tabular}

There is, however, no increase in the deviation as the load is increased suggesting that the origin of the reduced voltage is increased magnet leakage flux and not increased armature reactance. This seems reasonable in the context of the earlier FEA results as illustrated in Figs. 3 and 4.

In addition a small improvement in efficiency in the notchless machine ranging from $0.1-2.4$ percentage points was observed. Since the efficiency values in the table are based on input and output measurements, these small differences are questionable and should not be emphasized beyond simply noting that all data points do show improved efficiency. Efficiency improvement in the notchless design resulting from a smoother air gap flux density wave was one of the anticipated benefits and the data supports this idea. No dramatic impact on acoustic noise or vibration was observed.

One area of concern is the low overall efficiency exhibited by both the notched and notchless designs. At first glance one might be tempted to blame the magnetic bridge used for retaining the magnets in place for these low efficiencies but there are several other factors which the authors feel are much more significant in contributing to the low efficiencies.

- The quality and thickness of the steel used for the laminations. A low quality, 26 mil steel was used for all laminations. Typically, a much higher quality and thinner steel would be used for the frequencies seen by this machine.

- The stack length to diameter ratio is quite low. This machine is at the low power end of a series machines,

and the higher power (longer stack) machines exhibit significantly improved efficiencies.

- The increased eddy current losses associated with the quasi-squarewave flux density. Based on the technique presented by Slemon [6], it can be shown that the eddy current losses associated with the quasi-squarewave flux density produced by these machines is 2.1 times that for a sinusoidal flux density [7].

\section{CONCLUSIONS}

The work reported in this paper demonstrates that a PM rotor structure employing a thin iron bridge over the magnets can be successfully designed to serve several useful functions.

In particular the structure

- provides an effective means of magnet retention in the radial direction;

- allows use of rectangular rather than curved magnets;

- allows easy assembly of the rotor magnetic system-the reluctance forces are sufficient to retain the magnets in the axial direction;

- avoids the high $q$-axis inductance normally found in buried magnet designs.

It was also demonstrated that it is possible to design the bridge such that the required saturation occurs on top of the magnets (at the corners) and not at the sides of the magnets. This allows eliminating the lamination notches between magnets, yielding a simpler and less expensive rotor lamination. Tests also indicate that eliminating the notches reduces the total iron loss in the machine.

\section{REFERENCES}

[1] Michael W. Degner, "A performance model for a high pole number, buried permanent magnet alternator," Master's thesis, Dep. Mech. Eng., Univ. of Wisconsin-Madison, 1993.

[2] E. Richter, "Power density considerations for permanent magnet machines," Electric Machines and Electromechanics, vol. 4, pp. 21-32, July/Aug. 1979.

[3] AC Machine Design-Course Notes, Department of Engineering Professional Development, Univ. of Wisconsin-Madison, Short Course, Aug. 1993.

[4] K. J. Binns, M. S. N. Al-Din, and P. J. G. Lisboa, "Use of canned rotors in high-field permanent magnet machines," in IEE Proc. $B$, vol. 139, no. 5,1992 , pp. $471-477$.

[5] B. C. Mecrow, A. G. Jack, and J. M. Masterman, "Determination of rotor eddy current losses in permanent magnet machines," in IEE Conf. Elec. Machines and Drives, Sept. 1993, pp. 299-304.

[6] G. R. Slemon and X. Liu, "Core losses in permanent magnet motors," IEEE Trans. Magn., vol. 26, no. 5, pp. 1653-1655, Sept. 1990.

[7] A. M. Garcia, "Utilization of third harmonic voltages in DC power generation," Master's thesis, Dep. Elec. Eng., Univ. of WisconsinMadison, 1995.

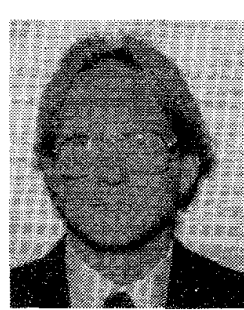

mechanical design.
Michael W. Degner received the B.S. and M.S. degrees in mechanical engineering from the University of Wisconsin-Madison in 1991 and 1993, respectively, and is currently completing the requirements for the Ph.D. degree in mechanical engineering at the University of Wisconsin-Madison. The focus of his Master's thesis was on the design and modeling. of a high pole number, permanent magnet alternator, and his Ph.D. research currently focuses on the control and design of sensorless induction motors. His interests include control systems and electro- 


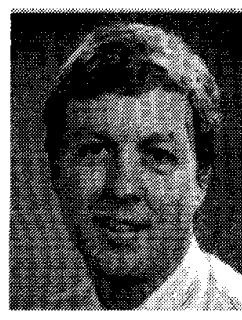

Richard Van Maaren (S'74-M'82) received the B.S. degree in electrical engineering from Michigan Technological University, Houghton, MI, in 1977.

From 1977-1982, he worked as an induction motor design engineer for the General Electric Company in the Hermetic Motor Division. From 1982 to the present, he has served the Kohler Company Generator Division, Kohler, WI, as a synchronous alternator design engineer and currently as supervisor of alternator engineering. $\mathrm{He}$ is responsible for the design of all wolnd field and permanent magnet machines. He holds 3 patents

Mr. Van Maaren is a registered professional engineer in the state of Wisconsin.

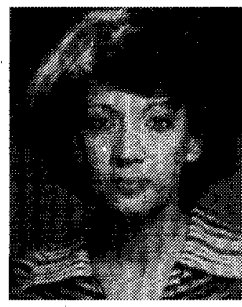

Azza Fahim received the B.S. and M.S. degrees from Cairo University, Egypt, in 1973 and 1977 both in electrical engineering. She conducted doctoral research in the area of finite element analysis of linear induction motors at Iowa State University and the University of Wisconsin-Madison, and received the Ph.D. degree from Cairo University in 1984.

She served as Associate Research Scientist at the National Research Center in Cairo, Egypt, was a Postdoctoral Research Fellow at the Technical University of Delft, The Netherlands, from 1986-1987, and was a Research Associate at the University of Wisconsin-Madison in 1989-1994. She is currently Research Assistant Professor at the Department of Electrical, Computer and Systems Engineering at Boston University. Her research is primarily concerned with the electromagnetic analysis of nonconventional electric machines, including linear and superconducting machines, and design techniques using finite element methods.

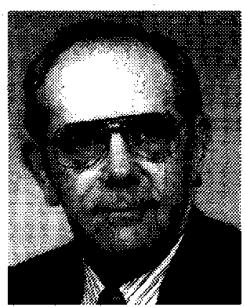

Donald W. Novotny (M'62-SM'77-F'87) received the B.S. and M.S. degrees in electrical engineering from the Illinois Institute of Technology, Chicago, in 1956 and 1957, and the Ph.D. degree from the University of Wisconsin-Madison in 1961.

Since 1961, he has been a member of the faculty at the University of Wisconsin-Madison where he is currently Grainger Professor of Power Electronics and Co-director of the Wisconsin Electric Machines and Power Electronics Consortium (WEMPEC), an educational and research support organization with more than 50 industry sponsors. He served as Chairman of the Electrical and Computer Engineering Department from 1976-1980 and as an Associate Director of the University-Industry Research Program from 1972-1974 and from 1980-1993. He has been active as a consultant to many organizations and has also been a Visiting Professor at Montana State University, the Technical University of Eindhoven, Eindhoven, Netherlands, the Catholic University of Leuven, Leuven, Belgium and a Fulbright Lecturer at the University of Ghent, Ghent, Belgium. He has published more than 100 technical articles on electric machines, variable frequency drives, and power electronic control of industrial system

Dr. Novotny received nine prize paper awards from the IEEE Industry Application Society. $\mathrm{He}$ is a member of ASEE, Sigma Xi, Eta Kappa Nu, and Tau Beta Pi, and is a Registered Professional Engineer in Wisconsin.

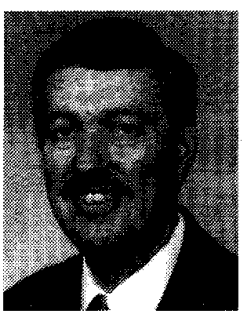

Robert D. Lorenz (S'83-M'84-SM'91) received the B.S., M.S., and Ph.D. degrees from the University of Wisconsin-Madison in 1969, 1970, and 1984 , respectively.

Since 1984, he has been a member of the faculty of the University of Wisconsin-Madison, where he is Professor of mechanical engineering and of electrical and computer engineering. In this position he acts as Associate Director of the Wisconsin Electric Machines and Power Electronics Consortium and as Co-Director of the Advanced Automation and Robotics Consortium. He was a Visiting Research Professor in the Electrical Drives Group of the Catholic University of Leuven, Leuven, Belgium, and in the Electrical Drives Institute of the Technical University of Aachen, West Germany, in the Summers of 1989 and the Summers of 1987 and 1991, and 1995, respectively. In 1969-1970, he did his Master Thesis research at the Technical University of Aachen, West Germany. From 1972-1982, he was a member of the research staff at the Gleason Works, in Rochester, NY. His current research interests include sensor integrated electromagnetic actuator technologies, real-time digital signal processing and estimation techniques, and ac drive and high-precision machine control technologies.

Dr. Lorenz is a past Chairman of the IEEE IAS Industrial Drives Committee, and is a member of the Industrial Automation and Control Committee, the Electrical Machines Committee, and the Industrial Power Converter Committee. He is an active consultant to many organizations and is a Registered Professional Engineer in the States of New York and Wisconsin. He is a member of the ASME, the ISA, and the SPIE.

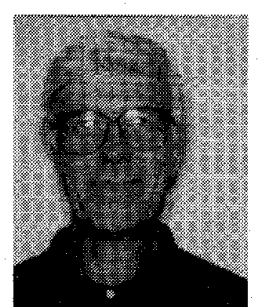

Charles D. Syverson received the B.S. degree from the University of Minnesota. For more than 20 years he has been a private consulting engineer doing new product design and development and prototyping for specialty motors and generators, including high-speed motors and alternators, compact computer disk-drive motors, brushless permanent magnet motors, switched reluctance motors, and large permanent magnet alternators. He is a holder of several patents in the area of rotating electrical machines, including the most recent involving high power density, high efficiency automotive style alternators. He has also recently developed and patented a hybrid automotive alternator design concept. He is active in alternative energy concepts development and seminars and works in conjunction with a small consortium of designers and prototyping houses doing contract product development. He is author of the book Wind Power. Mr. Syverson is a registered electrical engineer. 